\title{
Severe fetal bradycardia in a pregnant surgical patient despite normal oxygenation and blood pressure
}

[Bradycardie fotale sépère chez une opérée enceinte malgré une oxygénation et une tension artérielle normales]

Bill Y. Ong FrCPC, Ken Baron FrCPC, Eric L. Stearns FrCSC, Cynthia Baron FrCPC, Don Paetkau FrCPC, Ron Segstro FRCPC

\begin{abstract}
Purpose: To report and discuss a case of fetal bradycardia in a parturient under anesthesia for cholecystectomy despite normal maternal oxygenation and arterial blood pressure.

Clinical features: A 27-yr-old woman (gravida 2 para I), with a fetus of 34 weeks gestation, received general anesthesia for cholecystectomy. After anesthesia induction and tracheal intubation, anesthesia was maintained with oxygen, sevoflurane and iv remifentanil infusion. While preparing for surgery, the fetal heart rate decreased within about half a minute to 70 beats $\mathrm{min}^{-1}$ and remained at that level. The maternal blood pressure, heart rate and oxygen saturation were normal. An emergency Cesarean delivery was performed. The infant had Apgar scores of $I$ at one minute, 5 at five minutes, 7 at ten minutes and required resuscitation after birth.
\end{abstract}

Conclusion: Ideally, women having non-obstetric surgery during the third trimester of pregnancy will have intraoperative fetal heart rate monitoring.

Objectif : Présenter un cas de bradycardie fotale chez une parturiente sous anesthésie pour cholécystectomie malgré l'oxygénation et la tension artérielle maternelles normales.

Éléments cliniques : Une femme de 27 ans (gravida 2 para l), enceinte de 34 semaines, a subi une cholécystectomie sous anesthésie générale. Après l'induction de l'anesthésie et l'intubation endotrachéale, l'anesthésie a été maintenue avec de l'oxygène, du sévoflurane et une perfusion iv de rémifentanil. Pendant la préparation pour l'opération, la fréquence cardiaque fotale a chuté à 70 battements $\cdot \mathrm{min}^{-1}$ en moins de $30 \mathrm{sec}$ environ et est demeurée à ce niveau. La tension artérielle, la fréquence cardiaque et la saturation du sang en oxygène étaient normales chez la mère. Une césarienne d'urgence a été réalisée. L'enfant présentait un indice d'Apgar de 1 à une minute, de 5 à cinq minutes, de 7 à dix minutes et a dû être réanimé après la naissance.

Conclusion : Idéalement, il faut surveiller la fréquence cardiaque fotale peropératoire chez les parturientes qui subissent une opération non obstétricale au troisième trimestre de la grossesse.

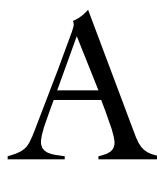

S many as $2 \%$ of pregnant women undergo non-obstetric surgery during pregnancy ${ }^{\mathrm{l}}$ and cholecystectomy is one of the common surgical procedures performed. Pancreatitis and cholecystitis can complicate cholelithiasis and lead to significant maternal and fetal morbidities. Some surgeons, therefore, advocate cholecystectomy during pregnancy rather than delaying surgery until delivery has occurred. ${ }^{2}$ One of the controversies in anesthesia for a pregnant patient having non-obstetric surgery is intraoperative fetal heart rate monitoring. A recent review on anesthesia for pregnant patients having non-obstetric surgery and obstetric anesthesia textbooks recommended fetal heart rate monitoring during anesthesia and surgery whenever possible. ${ }^{3-5}$ Some obstetricians believe that the fetus would not be compromised as long as maternal oxygenation and circulation remain normal. Horrigan $e t$ $a l^{6}$ suggested that fetal monitoring by obstetric personnel was unnecessary during surgery in pregnant patients. We report a case of fetal bradycardia in a parturient under anesthesia for cholecystectomy despite normal maternal oxygenation and arterial blood pressure.

From the Departments of Anesthesia and Obstetrics, Gynecology and Reproductive Sciences, University of Manitoba, Winnipeg, Manitoba, Canada.

Address correspondence to: Dr. B. Y. Ong, Department of Anesthesia, University of Manitoba, LB 315-60 Pearl St., Winnipeg, Manitoba

R3E 1X2, Canada. Phone: 204-787-3440; Fax: 204-787-4291; E-mail: ong@cc.umanitoba.ca

Accepted for publication May 5, 2003.

Revision accepted July 21, 2003. 


\section{Case report}

A 27-yr-old woman (gravida 2 para 1), with a fetus of 34 weeks gestation, was admitted to the hospital with recurrent biliary colic and cholelithiasis. The patient was otherwise healthy. On examination, the patient's blood pressure was $110 / 65 \mathrm{mmHg}$, heart rate was 80 beats. $\mathrm{min}^{-1}$, respiratory rate was 20 breaths. $\mathrm{min}^{-1}$, and temperature was $36.2^{\circ} \mathrm{C}$. The abdomen was tender, but showed no rebound tenderness. Murphy's sign was positive. Laboratory investigations showed a white blood count $15.9 \times 10^{9} \cdot \mathrm{L}^{-1}$, hemoglobin $103 \mathrm{~g} \cdot \mathrm{L}^{-1}$, serum alanine aminotransferase $43 \mathrm{U} \cdot \mathrm{L}^{-1}$, serum aspartate transaminase $47 \mathrm{U} \cdot \mathrm{L}^{-1}$, and serum gamma glutamyl transferase $25 \mathrm{U} \cdot \mathrm{L}^{-1}$. Fetal heart rate was 120 beats. $\mathrm{min}^{-1}$ with average variability. The patient received analgesic and antibiotic therapies. Two days later, the patient's temperature increased to $38.7^{\circ} \mathrm{C}$, respiratory rate increased to 32 breaths $\mathrm{min}^{-1}$, blood pressure was $120 / 70 \mathrm{mmHg}$. White blood count increased to $22 \times$ $10^{9} \cdot \mathrm{L}^{-1}$ and showed a left shift. The attending surgeon decided to perform a cholecystectomy.

After oral citrate antacid prophylaxis, a low thoracic epidural catheter was inserted in the sitting position with no complication. A test dose of $3 \mathrm{~mL} 2 \%$ lidocaine with $5 \mu \mathrm{g} \cdot \mathrm{L}^{-1}$ epinephrine was injected. The patient then assumed a supine position with a wedge under the right hip. The patient was monitored with continuous electrocardiogram, non-invasive blood pressure, and pulse oximetry. External fetal heart rate monitoring was performed by an obstetric nurse. Fetal heart rate was about 130 beats $\mathrm{min}^{-1}$ before the start of anesthesia. Maternal blood pressure was 130/70 $\mathrm{mmHg}$, heart rate 110 beats. $\mathrm{min}^{-1}$ and oxygen saturation $99 \%$ prior to induction of anesthesia. After preoxygenation with $100 \%$ oxygen and application of cricoid pressure, anesthesia was induced with fentanyl $150 \mu \mathrm{g}$, propofol $150 \mathrm{mg}$ and rocuronium $50 \mathrm{mg}$. An oral endotracheal tube was inserted and the position was confirmed by auscultation and end-tidal carbon dioxide monitoring. Anesthesia was maintained with $100 \%$ oxygen, sevoflurane at an end-tidal concentration of $0.6 \%$, and remifentanil $0.15 \mu \mathrm{g} \cdot \mathrm{kg}^{-1} \cdot \mathrm{min}^{-1}$. Arterial blood pressure was $120 / 75 \mathrm{mmHg}$, heart rate was 100 beats. $\mathrm{min}^{-1}$, maternal oxygen saturation was $99 \%$, end-tidal $\mathrm{CO}_{2}$ was $36 \mathrm{mmHg}$ for the first 15 min after the start of anesthesia. The fetal heart rate was 120 beats $\mathrm{min}^{-1}$ with reduced variability. While preparing for surgery but before surgical incision, the fetal heart rate decreased over a span of about half a minute to 70 beats. $\mathrm{min}^{-1}$. The obstetrician tried to move the uterus further off the midline, and move the fetal head out of the pelvis. The maternal blood pressure, heart rate and oxygen saturation had not changed during this time. Fetal heart rate decreased further to 60 beats. $\mathrm{min}^{-1}$. An emergency Cesarean delivery was performed. The infant had Apgar scores of 1 at one minute, 5 at five minutes and 7 at ten minutes and required resuscitation after birth. The umbilical cord arterial gases were: $\mathrm{PO}_{2} 7 \mathrm{mmHg}, \mathrm{PCO}_{2} 64$ $\mathrm{mmHg}, \mathrm{pH}$ 7.17. The umbilical cord venous gases were: $\mathrm{PO}_{2} 13 \mathrm{mmHg}, \mathrm{PCO}_{2} 62 \mathrm{mmHg}, \mathrm{pH} 7.18$. The umbilical cord was coiled and twisted tight on itself like a telephone cord. There was no knot in the umbilical cord. In his operative report, the obstetrician commented that "the (umbilical) cord was noted to be very tense and wound up very much like a rubber band in a model aircraft."

After completion of the Cesarean delivery, the surgeon completed the cholecystectomy without any problem. Nitrous oxide was added after delivery of the infant and the patient remained in stable condition throughout the two surgical procedures.

\section{Discussion}

The intraoperative monitoring of the fetus in a pregnant patient having non-obstetric surgery is a controversial subject. A recent review on anesthesia for pregnant patients having non-obstetric surgery and obstetric anesthesia textbooks recommended fetal heart rate monitoring during anesthesia and surgery when possible..$^{3-5}$ These recommendations are based on anecdotal evidence of fetal compromise identified by fetal heart rate monitoring. Katz et al. ${ }^{7}$ demonstrated fetal tachycardia during accidental maternal hypoxemia and return to baseline fetal heart rate after maternal ventilation was corrected. There is no large systematic study of intraoperative fetal heart rates and subsequent events after non-obstetric surgery during pregnancy.

Amos et al. ${ }^{8}$ reported two intra-uterine fetal deaths and two incomplete abortions after laparoscopic procedures during pregnancy. Three of the four adverse events occurred in the postoperative period. Duncan et al. ${ }^{9}$ compared 2,565 women in Manitoba, Canada who had surgery during pregnancy against matched controls who did not have surgery. They found that surgery during pregnancy was associated with a significantly higher rate of spontaneous abortion. Mazze and Kallen ${ }^{10}$ studied 5,405 neonates born after their mothers had surgery during pregnancy using data from a Swedish registry. They found an association between surgery during pregnancy and low birth weight babies as well as death within $168 \mathrm{hr}$ of birth. Kort et al. ${ }^{11}$ reported that preterm labour was more common after surgery during pregnancy. Reedy et al. ${ }^{12}$ used data from three Swedish Health Registries to compare the neonatal outcomes after maternal 
laparoscopy or laparotomy during pregnancy. The women who had laparoscopy or laparotomy had an increased risk of delivering low-birth-weight babies (< $2500 \mathrm{~g}$ ), delivering before 37 weeks gestation and delivering growth-restricted babies.

These retrospective reviews cannot separate the effects of maternal diseases, surgical interventions and anesthetic techniques on the adverse outcomes associated with surgery during pregnancy. A controlled study is needed to determine whether certain intraoperative fetal heart rate changes might be associated with adverse fetal effects.

Some obstetricians believe that the fetus would not be compromised as long as maternal oxygenation and circulation remain normal. They recommend assessing the fetal heart rate and uterine activity before and after the surgical procedure. Horrigan et al. ${ }^{6}$ performed a review of case reports of non-obstetric surgery during pregnancy, published between 1966 and 1995. Based on the case reports and their review of maternal-fetal physiology, the authors suggested that intraoperative fetal monitoring by obstetric personnel is unnecessary.

Intraoperative fetal heart rate monitoring requires proper obstetrical and neonatal personnel to be interpreted correctly. The fetal heart rates during anesthesia and surgical procedures in the absence of uterine contractions may be different from fetal heart rate changes in labour. While the absence of fetal heart rate variability can be a significant indicator of fetal stress during labour, fetal heart rate variability is significantly reduced in healthy fetuses under anesthesia. Misinterpretation of intraoperative fetal heart rate variability changes has led to premature delivery ${ }^{13}$ of an infant who required endotracheal intubation and mechanical ventilation. The infant's Apgar scores were 0,2 and 6 at one, five and ten minutes. The $\mathrm{pH}$ of the umbilical vessel was normal $(\mathrm{pH} 7.23$ mixed arterial/venous) indicating that the lack of beat-to-beat variation was not a result of fetal distress.

In the case described, the 34 weeks gestational age of the fetus led us to take a proactive course. We elected to monitor the fetus in the intraoperative period and intervened immediately when the fetal heart rate decreased to 60 beats. $\mathrm{min}^{-1}$. The cause of the severe fetal bradycardia is unknown. The tense and tightly wound umbilical cord observed by the obstetrician might have produced some impairment of umbilical blood flow even before the anesthetic. Under anesthesia, the fetus might come to lie on the umbilical cord and compressed the umbilical cord against the uterine wall. The combination of increased vascular resistance from the tightly coiled state and further external compression might have caused a marked reduction in umbilical cir- culation. Impaired umbilical blood flow could have led to fetal hypoxia even when maternal oxygenation and circulation were normal. If we had utilized a different regimen such as monitoring the fetal heart rates during a preoperative and then a postoperative period, the fetus might have suffered a much more prolonged period of stress and an adverse outcome.

In summary, we have reported a case of severe fetal bradycardia in a pregnant surgical patient despite normal maternal oxygenation and blood pressure. This is consistent with previous reports of intra-uterine fetal deaths, fetal growth retardation and abortions associated with surgical procedures during pregnancy. ${ }^{8-12}$ Ideally, women having non-obstetric surgery during the third trimester of pregnancy will have intraoperative fetal heart rate monitoring.

\section{References}

1 Brodsky JB, Cohen EN, Brown BW Jr, Wu ML, Whitcher $C$. Surgery during pregnancy and fetal outcome. Am J Obstet Gynecol 1980; 138: 1165-7.

2 Muench J, Albrink M, Serafini F, Rosemurgy A, Carey $L$, Murr MM. Delay in treatment of biliary disease during pregnancy increases morbidity and can be avoided with safe laparoscopic cholecystectomy. Am Surg 2001; 67: 539-43.

3 Rosen MA. Management of anesthesia for the pregnant surgical patient. Anesthesiology 1999; 91: 1159-63.

4 Cohen SE. Nonobstetric surgery during pregnancy. In: Chestnut DH (Ed). Obstetric Anesthesia, 2nd ed. 1999; 16: 293-4.

5 Levinson G, Shnider SM. Anesthesia for surgery during pregnancy. In: Shnider SM, Levinson G (Eds.). Anesthesia for Obstetrics, 3rd ed. 1993; 14: 276.

6 Horrigan TJ, Villarreal R, Weinstein L. Are obstetrical personnel required for intraoperative fetal monitoring during nonobstetric sugery? J Perinatol 1999; 19: 124-6.

7 Katz JD, Hook R, Barash PG. Fetal heart rate monitoring in pregnant patients undergoing surgery. Am J Obstet Gynecol 1976; 125: 267-9.

8 Amos JD, Schorr SJ, Norman PF, et al. Laparoscopic surgery during pregnancy. Am J Surg 1996; 171: 435-7.

9 Duncan PG, Pope WD, Cohen MM, Greer N. Fetal risk of anesthesia and surgery during pregnancy.

Anesthesiology 1986; 64: 790-4.

10 Mazze RI, Kallen B. Reproductive outcome after anesthesia and operation during pregnancy. A registry study of 5405 cases. Am J Obstet Gynecol 1989; 161: 1178-85.

11 Kort B, Katz VL, Watson WJ. The effect of nonobstetric operation during pregnancy. Surg Gynecol Obstet 1993; 177: 371-6. 
12 Reedy MB, Kallen B, Kuehl TJ. Laparoscopy during pregnancy: a study of five fetal outcome parameters with use of the Swedish Health Registry. Am J Obstet Gynecol 1997; 177: 673-9.

13 Immer-Bansi A, Immer FF, Henle S, Sporri S, PetersenFelix $S$. Unnecessary emergency caesarean section due to silent CTG during anaesthesia? Br J Anaesth 2001; 87: 791-3.

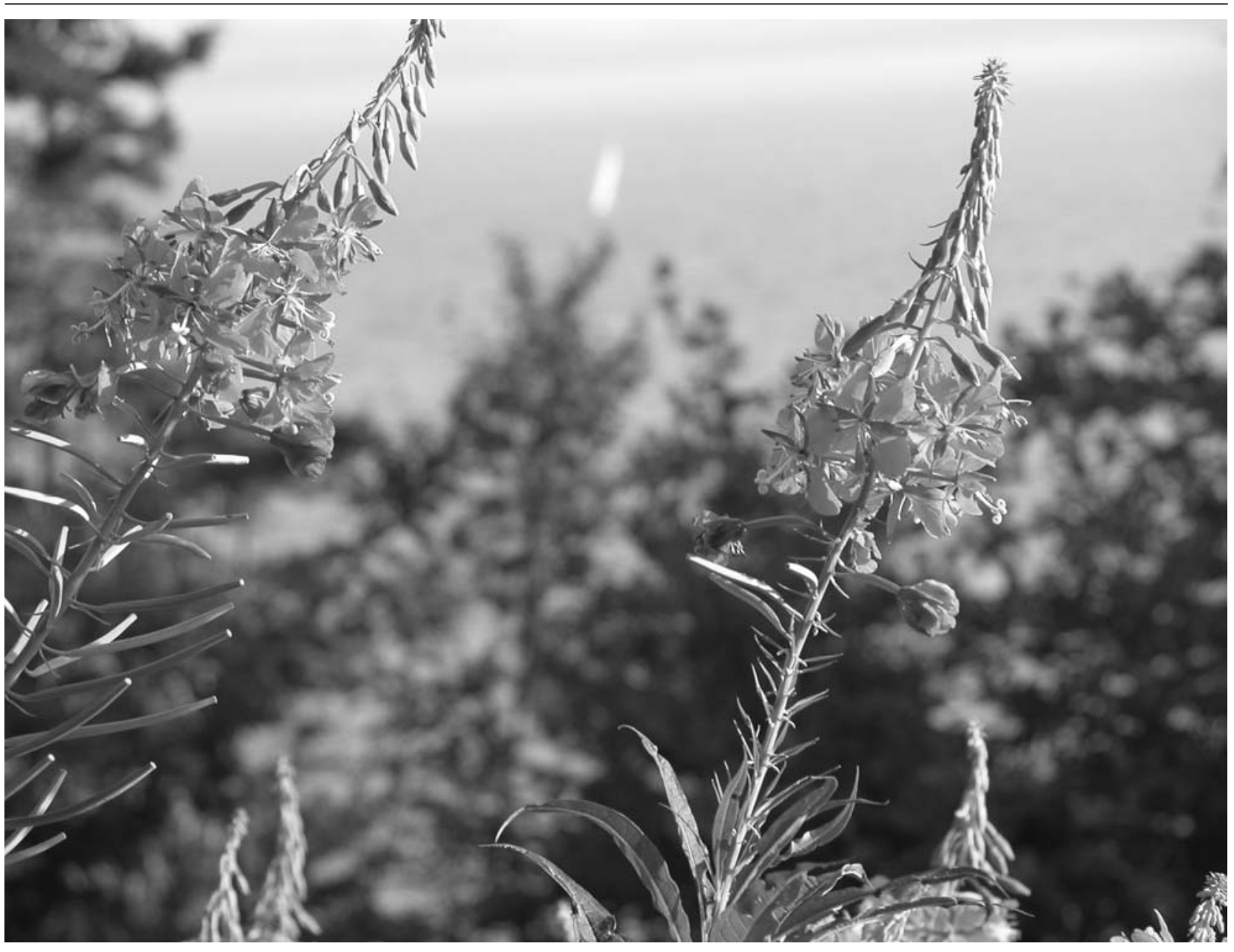

Parc Forillon - Québec 